\section{Reckless Frog in the Well}

\author{
Geon Ho Bahn \\ Editor-in-Chief, Korean Academy of Child and Adolescent Psychiatry
}

Journal of the Korean Academy of Child and Adolescent Psychiatry has made some significant changes this year on 29th volume, and one of them is switching to be an Englishonly journal. We anticipated it to be a challenging work; however, it has proven to be much more difficult than we anticipated and with new challenges. For instance, writing, reading, and reviewing articles in English, which is a second language for all of us, has proven to be very different and difficult than simply finding and reading an existing article.

In this volume, four original articles and one book review got published. Soo-Young Bhang et al. identified the process of psychosocial assessment, the experience of intervention, and improvement after the Sewol Ferry Disaster, April 2014. They interviewed survivors from Danwon high school students who were on the Ferry. The rest of the published articles coincidently all were about the theme of autism spectrum disorder (ASD). From the correlation analysis between childhood autism rating scale (CARS) and autism diagnostic observation schedule, Soon-Beom Hong et al. suggested two cut-off scores of CARS as a diagnostic tool and a screening tool for ASD. The cut-off score of CARS as a screening tool would be helpful to evaluate kids with subthreshold of diagnostic criteria as ASD. Hyo-Won Kim et al. estimated the ASD prevalence under DSM-5 and DSM-IV. Young-Sook Kwak et al. investigated the effect of social skills training on facial emotion recognition and discrimination in children with attention-deficit/hyperactivity disorder and ASD. Heejeong
Yoo wrote a book review on "The Death of Expertise: The Campaign against Established Knowledge and Why it Matters" written by Tom Nichols. With many self-acclaimed "experts" appearing recently, this book discusses and offers insights on how to react to and deal with self-claimed experts.

"Frog in the well" is an old Korean proverb, used to describe an individual who cannot or refuses to see the big picture because of being sheltered and close-minded. If it ever comes out, it sees the world beyond its imagination, filled with new things and endless world. It might get scared, encountering new predators that present new types of danger to its life. It feels and misses the comfort of the old way of being in its well and goes back to the well. However, one day, it closes its eyes and sees all that the new world presented before it and wishes it could be a little bit braver. It is good to live in the well, or to travel around the world. Editorial committee members have seen the new world that we could be part of- "Impact Factor," "Scopus," "SCIE," "Web of Science" etc. We are taking on new challenges to be a reckless frog that leaps to jump into the new world outside the well. In order for us to succeed and make the world outside our comfort zone our new world, we need help from our colleagues. We need to create objective measures to gauge what we need and to do better. With this new journey we chose, we hope that our colleagues will join us and help us navigate the new challenges by providing us with feedback and advice.

This is an Open Access article distributed under the terms of the Creative Common Attribution Non-Commercial License (https://creativecommons.org/licenses/by-nc/4.0) which permits unrestricted non-commercial use, distribution, and reproduction in any medium, provided the original work is properly cited. 